TITLE:

\title{
New evidence from observations of progressions of mandrills (Mandrillus sphinx): a multilevel or non-nested society?
}

\author{
$\operatorname{AUTHOR}(\mathrm{S})$ : \\ Hongo, Shun
}

\section{CITATION:}

Hongo, Shun. New evidence from observations of progressions of mandrills (Mandrillus sphinx): a multilevel or non-nested society?. Primates 2014, 55(4): 473-481

\section{ISSUE DATE:}

2014-08-05

URL:

http://hdl.handle.net/2433/200186

\section{RIGHT:}

The final publication is available at Springer via http://dx.doi.org/10.1007/s10329-0140438-y.; This is not the published version. Please cite only the published version.; この論 文は出版社版でありません。引用の際には出版社版をご確認ご利用ください。 
1 Title of paper: New evidence from observations of progressions of mandrills (Mandrillus sphinx):

2 a multilevel or non-nested society?

3

4 Author's name: Shun Hongo

5 Affiliation: Graduate School of Science, Kyoto University

6 Address: Kitashirakawa-Oiwakecho, Sakyo-ku Kyoto-shi, Kyoto, 606-8502, Japan

7

$8 \quad$ E-mail: hongo@jinrui.zool.kyoto-u.ac.jp

9 Phone: (+81) 757534085

$10 \quad$ Fax: $(+81) 757534115$

11

12 The final publication is available at link.springer.com.

13 http://link.springer.com/article/10.1007\%2Fs10329-014-0438-y

14

15

16

17

18

19

20

21

22

23

24 


\section{Abstract}

African papionins are well known for the diversity of their social systems, ranging from

27 multilevel societies based on the one-male-multifemale units (OMUs), to non-nested societies.

28 However, the nature of Mandrillus societies is still unclear due to difficult observational conditions in the dense forests of central Africa. To discuss characteristics of mandrill societies and their social systems, I analysed the age-sex compositions, behaviours, and progression

31 patterns of their horde/subgroups using video images of them crossing open places. The

32 progressions were very cohesive, and the very large aggregations (169-442 individuals) had only

$33 \quad 3-6$ adult males (1.4-1.8\% of all individuals) and 11-32 subadult males (6.5-7.2\%). No herding

34 behaviours were observed in the males and most of small clusters within the progressions were not analogous to OMUs of a multilevel society, but consisted of only adult females and immatures.

36 Their progressions under alerting circumstances showed patterns similar to those in a non-nested

37 social system: females with dependent infants concentrated toward the rear part, while adult and subadult males did so toward the front. These results suggest that cohesive aggregations and

39 female-biased sex ratio are common characteristics of the mandrill species. Mandrills might form

40 female-bonded and non-nested societies, although their fission-fusion dynamics may be different

41 from those typical in 'savannah baboons'.

\section{Keywords}

44 Mandrill, Social system, Age-sex composition, Progression, Moukalaba-Doudou 


\section{Introduction}

Primates exhibit tremendous diversity in their social systems. Although many researchers

51 have discussed the evolutionary history of social systems for more than five decades, it is still one

52 of the central arguments in primatology (Crook and Gartlan 1966; Itani 1977; Kappeler and van

53 Schaik 2002; Shultz et al. 2011), specifically in relation to the African papionins (subtribe

54 Papionina). Their social systems vary among species (Swedell 2011). Hamadryas baboons (Papio

55 hamadryas) and geladas (Theropithecus gelada) form multilevel societies, in which a number of

56 one-male-multifemale units (OMUs) are nested within a social unit termed 'band'; other Papio species, often referred to as the 'savannah baboons' ( $P$. anubis, cynocephalus and ursinus), live in non-nested societies, in which multiple females and typically multiple males form a cohesive female-bonded group. This variety has been explained as reflections of past selection pressures on different populations. For example, Henzi and Barrett (2003) hypothesized that hamadryas baboons developed the multilevel society for adaptations to both the high predation risk and the scarce resources and shelters, whilst savannah baboons in the less harsh area remained non-nested.

63 Nevertheless, most of these discussions have been focused only on the species in the arid areas,

64 and mandrills (Mandrillus sphinx) nor drills (M. leucophaeus) have not been included in these arguments. It is essential to explore the nature of Mandrillus societies, though they are not the sister taxon of Papio-Theropithecus but of eye-lid mangabeys (Cercocebus spp.) (Harris 2000), to develop a comprehensive understanding of the social evolution of African papionins. Their large home range $\left(81 \mathrm{~km}^{2}\right.$ by MCP method based on a 6-year-study, White et al. 2010) and poor visibility in the dense rainforest make it difficult for field researchers to observe the behaviours of wild Mandrillus populations and the nature of their societies is still unclear.

71 Besides, there are some conflicting arguments about their social systems. Their large aggregations, 72 termed 'hordes', have originally been considered as multilevel societies and fully-matured males 
were believed to be leaders of each OMU, mainly because of the various sizes of aggregations,

74 from several tens to hundreds, and frequent fission-fusion (mandrills, Hoshino et al. 1984; Rogers et al. 1996; drills, Gartlan 1970). More recently, Abernethy et al. (2002) reported a considerably different view of mandrill society. They argued that mandrills form a stable social unit and rarely divide into small subgroups. In addition, the hordes had only 1-17 adult males and the number of mature males in the hordes fluctuated seasonally according to the number of females with sexual tumescence. Based on the results, they hypothesized that mandrills live in a female-led society, where males are not resident members but migrators, who enter hordes at the onset of seasonal cycles in the females. Studies on vocal communications (Kudo 1987) and social network analysis of a small captive group of 19 individuals (Bret et al. 2013) also suggested the important role of females on group cohesion. In this paper, the term 'horde' is used for a large group of mandrills around which any other group is not observed nor heard, 'subgroup' is used for a group that has evidently divided from a horde, and 'aggregation' includes both 'horde' and 'subgroup'. allow us to consider Mandrillus social system. On the one hand, in OMU-based multilevel societies, leader males herd their females by exhibiting aggressions, like neck bites, and through soliciting behaviours, such as looking back and gazing (Kummer 1968; Mori 1979; Swedell and Schreier 2009). As a consequence, members of the same OMU, which consists of 2-28

91 individuals (Grüter and Zinner 2004), always stay together and rarely intermingle with other

92 OMUs, and no females are found outside the OMUs (Kummer 1968; Snyder-Mackler et al. 2012).

93 On the other hand, based on studies on non-nested societies of the savannah baboons, they were

94 found to travel in consistent patterns of progression. Subadult males tend to be in the front part of the march (Rhine et al. 1979). Adult males, which are the most robust animals to external threats,

96 tend to concentrate toward the side of potentially danger, such as the front part when entering 
open waterholes (Rhine 1975; Rhine and Tilson 1987). On the contrary, females with a dependant infant, which are the most sensitive to threats, tend to remain in the rear part of the march when they enter the waterholes (Rhine 1975). Additionally, related females form the core of their group, and strong bonds between males and females do not always exist (Altmann 1980; Silk et al. 2006). to 30 individuals, which have one or two males and several females, could be found within one aggregation, and 3) all females would be near at least one male. On the contrary, if mandrills live in a non-nested society, 1) adult and subadult males may occur mainly in the front part of the progressions, especially when they are on the alert, 2) females with infants may aggregate in the rear part when they proceed with caution, and 3) small clusters without males may be observed. The aim of this study is to examine these predictions by observations on their progressions.

Methods

I conducted the study over 25 months, between August 2009 and September 2013, in the

112 northeastern part (approximately $280 \mathrm{~km}^{2}$ ) of the Moukalaba-Doudou National Park, Gabon. The

113 annual rainfall in the study area was 1,583-2,163 mm (2002-2006, Takenoshita et al. 2008), and

114 the minimum and maximum temperatures were $19.4-25.0{ }^{\circ} \mathrm{C}$ and $27.6-34.1{ }^{\circ} \mathrm{C}(2006-2009$,

115 PROCOBHA researchers team, unpublished data). There are two distinct seasons in this region,

116 a rainy season from October to April, and a dry season from May to September. A more detailed

117 description of this site has been provided in Takenoshita et al. (2008).

118 I searched for mandrill hordes and followed them for as long a time as possible. Whenever

119 a horde came near an open place, such as a logging road or a river, I tried to record the progression

120 of all members crossing the area using a video camera. When the horde divided into several 
121 subgroups, one of them was focused for the recording. In order to ensure that all the members of one horde or subgroup were recorded, I confirmed the absence of a preceding or remnant

123 individual by auditory information and observation from the beginning of the passage to at least

$1245 \mathrm{~min}$ after the last individual had crossed. After the recording, I also confirmed the absence of 125 other traces within $100 \mathrm{~m}$ of each side from the crossing point.

126 I carried out four types of analysis using the video images. First, I categorized each animal

127 into 6 age-sex classes as shown in Table 1. Females with sexual swellings could not be counted 128 precisely because of the long distances from the focal aggregations. When the individuals 129 repassed reversely, I counted them and subtracted their number from that of the crossed 130 individuals to ensure a precise count. Pubescent males (PMs) and adult females that were not 131 holding infants (non-FIs) were indistinguishable from each other until their genital parts were 132 displayed, because their body sizes and morphological features are very similar (Abernethy et al.

133 2002). Therefore, these unidentified individuals were classified into the two classes in a ratio of

134 the identified ones. In Case 1, however, it was impossible to sort them since none had clearly 135 displayed its genital parts. Socionomic sex ratio (SSR, the number of adult females per adult and 136 subadult males) was also calculated in each case, other than in Case 1. Secondly, behaviours 137 related to herding, in other words, aggression (bite, grab, approach, and bark), look-back (look at 138 another behind the performer), and facing (gaze at each other), were recorded with their directions 139 and the age-sex class of the individuals involved. Further, in order to evaluate degree of alertness 140 against human observers in each case, I noted the number of individuals looking at the observers.

141 I also noted appearance time from the bushes and arrival time at the other side of the open place

142 for each individual to an accuracy of one-tenth of a second, and calculated their crossing speeds.

143 When the vigilance levels of individuals are high, their crossing speeds should be fast to avoid

144 potential risk. Therefore, I compared them among cases using the Mood's median test with the 
145 Bonferroni correction. Lastly, randomization tests of 100,000 iterations were performed by case

146 in the progression orders, in order to evaluate the concentration of animals belonging to several

147 age-sex classes towards the fore or rear of a progression. Medians of the order in adult males

148 (mAM), subadult males (mSM), and females holding an infant (mFI) were used for the test

149 statistic. Then I divided each progression into clusters when an inter-arrival time between

150 individuals was more than $10 \mathrm{~s}$, and the age-sex class compositions of them were noted only when

151 they contained 30 or less individuals to facilitate their comparison with the OMUs. All statistical

152 tests in this paper were two-tailed and conducted using R 3.0.0 software (R Core Team 2013). A

$153 \mathrm{p}$ value of 0.05 or lower was considered significant and that of 0.08 or lower was treated as a

154 tendency towards significance.

156 Results

157 Description of each passage case

158 I searched for mandrill hordes for 432 days, and located them 47 times. I also observed

15911 solitary males and one bachelor group of two adult males. I was able to record full members

160 of a mandrill large aggregation three times in total. I could not confirm if they were the same ones,

161 because I did not find any identical individual among cases. I have described the circumstances 162 in each case below.

164 horde and followed it from 10:09. It fissioned into several subgroups and, after a few minutes,

165 crossed fallen trees over a river approximately $10 \mathrm{~m}$ wide. We focused on one subgroup and

166 recorded it during the crossing. Distance between the focal subgroup and us was approximately

$16750 \mathrm{~m}$ and it was at least $300 \mathrm{~m}$ apart from the other subgroups. A total of 169 individuals passed

168 on the same tree during the $4 \mathrm{~min} 20 \mathrm{~s}$ period. About $10 \mathrm{~min}$ after they arrived at the other bank, 
they fused with the other subgroups, which had also apparently gone over other fallen trees.

walked on a logging road that was $2 \mathrm{~m}$ wide, we heard female mandrills' long-distant calls in the

172 bush at a distance of approximately $20 \mathrm{~m}$. We receded approximately $10 \mathrm{~m}$ and waited in hiding

173 for 5 minutes. Then a horde began to cross the road. The distance between the horde and us was approximately $30 \mathrm{~m}$. A total of 352 individuals passed during the $3 \mathrm{~min} 50 \mathrm{~s}$ period, and two of them repassed once reversely. Thus, the total number of members in the horde was 350 . We did

176 not hear any other noise or call from outside the focal horde. Width of the progression was about $17710 \mathrm{~m}$.

logging road and heard long-distance calls and alert calls of mandrills in the bush from one side

180 of the road. Then three individuals (the age-sex class could not be identified) crossed the road and

181 video recording was started from the fourth individual crossing. We knew this was a subgroup because we heard other individuals at a distance of at least 200-300 m away from the focal subgroup. The crossing was at a distance of approximately $30 \mathrm{~m}$ away from us. A total of 451

184 members passed during the $11 \min 7 \mathrm{~s}$ period, and nine repassed once reversely. Thus, the total number in the subgroup was 442 . Width of the progression was approximately $5 \mathrm{~m}$.

\section{Age-sex class composition}

Horde/subgroup sizes and age-sex class compositions of each case with those of mandrills in other sites and other terrestrial African papionin species are shown in Table 2. All three aggregations, which included two subgroups, contained at least 169-442 individuals. They

191 were larger than the bands and groups of other African papionins. In the aggregations that I

192 observed, adult males accounted for only $1.4-1.8 \%$, which were much lower than the other 
193 African papionins, and subadult males for 6.5-7.2\%. Then the SSR was 4.45 and 4.51 in Case 2

194 and 3, respectively. These tended to be higher when compared with the other species.

195

196 Herding behaviour

197 I observed 3 instances of grab and 11 of look-backs, but no facing was observed. Two out

198 of the three grabs were by adult or subadult males towards juveniles who overtook them, and 8

199 out of the 11 look-backs were performed by adult females towards juveniles or their infants. None

200 of these behaviours was observed between adult or subadult males and adult females.

201

202

Alertness during crossing

203

Only $12(7.1 \%)$ individuals gazed at the observers during the passage in Case 1, while 141 (40.3\%) and 349 (79.5\%) animals did so in Case 2 and 3, respectively.

The crossing speeds were significantly higher in Case 2 (median [min-max] $=3.33[0.22-$

$6.67] \mathrm{m} / \mathrm{sec})$ than in Case $3(1.33[0.16-5.00] \mathrm{m} / \mathrm{sec})$ and Case $1(0.53[0.06-1.91] \mathrm{m} / \mathrm{sec})$. Further, those in Case 3 were higher than in Case 1 (Mood's median test with Bonferroni correlation, Case 1 vs. Case 2, $\mathrm{p}<0.01$; Case 2 vs. Case 3, p $<0.01$; Case 3 vs. Case $1, \mathrm{p}<0.01$ ). Thirteen individuals paused on the tree for an average of $15.5 \mathrm{~s}$ in Case 1 , whereas none did so in the other cases. These results indicate that the mandrills of Case 2, and subsequently of Case 3, were on a

211 high alert due to the presence of the observers, and they crossed the open places with caution,

212 whereas those of Case 1 were at a relatively lower degree of alertness.

Patterns of progression order

Patterns of progression orders are presented in Fig. 1. In Case 1 (Fig. 1a), subadult males

216 (SMs) were significantly concentrated towards the front of the progression (randomization test, 
$217 \mathrm{mSM}=36, \mathrm{p}=0.03)$, but the patterns of the concentration of adult males (AMs) and females

218 holding an infant (FIs) were not statistically significant $(\mathrm{mAM}=66, \mathrm{p}=\mathrm{n} . \mathrm{s} ; \mathrm{mFI}=114.5, \mathrm{p}=$ 219 n.s). In Case 2 (Fig. 1b), both AMs and SMs were concentrated towards the front (mAM = 17, p $220<0.01 ; \mathrm{mSM}=69, \mathrm{p}<0.01)$ and FIs were towards the back $(\mathrm{mFI}=225, \mathrm{p}<0.01)$. In Case 3 (Fig. 1c), FIs were concentrated towards the back $(\mathrm{mFI}=303, \mathrm{p}<0.01)$ and SMs showed a tendency of concentration towards the front $(\mathrm{mSM}=143, \mathrm{p}=0.076)$, though the pattern of AMs was not statistically significant $(\mathrm{mAM}=164, \mathrm{p}=\mathrm{n} . \mathrm{s})$.

Six small clusters were detected in the progressions. Their compositions were as follows:

$(1 \mathrm{AM}+2[\mathrm{PM} /$ non-FI $]+1 \mathrm{~J})$ and $(2 \mathrm{AF}+3[\mathrm{PM} /$ non-FI $]+3 \mathrm{~J}+2 \mathrm{I})$ in Case $1 ;(1 \mathrm{AF}+1[\mathrm{PM} /$ non$\mathrm{FI}])$ and $(7 \mathrm{AF}+11 \mathrm{~J})$ in Case $3 ;(2 \mathrm{AF}+1[\mathrm{PM} /$ non-FI $]+2 \mathrm{~J})$ and $(1 \mathrm{AF}+2 \mathrm{~J})$ in the reversely repassed animals of Case 3. Although the first one can be identical to a OMU, most of the clusters did not represent a clear analogy for the OMU of a multilevel society. Indeed, 5 out of the 6 clusters did not include adult nor subadult males.

\section{Discussion}

The mandrills recorded in this study formed very cohesive progressions when they crossed an open area. Every aggregation of more than a hundred was in the form of long queue with a width of $10 \mathrm{~m}$ or less. Cohesive aggregations of mandrills were also reported in Campo and Lopé (Hoshino et al. 1984; Rogers et al. 1996; Abernethy et al. 2002). In terms of age-sex compositions, all three cases included only a few adult males and the SSR were more biased towards females than those in the other African papionins, as is the case in the other mandrill studies (Table 2). Thus, cohesive aggregation and female-biased sex ratio could be common characteristics in mandrills. Fluctuation in the proportion of adult males was not observed in this

240 study probably due to the limited sample size. The days that I observed the progressions 
241 correspond with the season of low or moderate number of adult males within a horde in Lopé,

242 where the fruiting phenology is similar to Moukalaba (Abernethy et al. 2002). I also observed

243 solitary males and, just for once, a bachelor group within the study site. Possibly high proportion

244 of males wandering outside hordes, as well as higher mortality of males (Setchell et al. 2005),

245 may cause the extremely low proportion of adult males in the hordes. Since bachelor mandrill

246 groups have not been observed in the other sites (Hoshino et al. 1984; Rogers et al. 1996;

247 Abernethy et al. 2002), more information on wandering males is needed.

248 No aggressive or soliciting behaviour was observed between adult or subadult males and

249 adult females within the progressions. Most of the look-backs, by which animals monitor the

250 identity of their followers (Sueur and Petit 2010), were observed between adult females and their

251 putative offspring. Moreover, most observed clusters did not have compositions analogous to the

252 OMUs but included only adult females and immatures. These results suggest the bonds among

253 females and immatures, which is analogous to female-bonded non-nested societies of savannah

254 baboons (Altmann 1980; Silk et al. 2006). Abernethy et al. (2002) also mentioned the absence of

255 OMUs in the hordes, and Bret et al. (2013) suggested the central role of females on mandrill group

256 cohesion.

257 Adult females holding infants were concentrated towards the back of the progression in

258 Case 2 and 3, when the animals were on a high alert. This pattern was not observed in the less

259 cautious Case 1 (Fig. 1). On the contrary, adult males in Case 2 (but not in Case 3) were

260 significantly concentrated towards the front, and this was not true in Case 1 . Further, subadult

261 males were significantly or nearly significantly concentrated towards the front in all cases.

262 In conclusion, the behaviours and the progression patterns of mandrills in Moukalaba

263 were not analogous to those in the OMU-based multilevel societies but to those in savannah

264 baboons. Although the results should be interpreted carefully due to limited sample size, they 
indicate that mandrills may form non-nested societies with strong bonds among females. In the terms of the subgrouping, however, it remains possible that mandrill hordes are different from the cohesive savannah baboon groups. Indeed, subgroupings were observed in two out of the three cases in the present study, as well as in several previous studies on both two Mandrillus species (Hoshino et al. 1984; Astaras et al. 2008) and in Cercocebus mangabeys (Mitani 1989; Range and Fischer 2004). Abernethy et al. (2002) also observed the short-term subgrouping for at least a few days just after their passage of open places, and White et al. (2010) observed regular subgrouping of the same horde. We should consider the social organization and fission-fusion dynamics separately (Aurelli et al., 2008; Grueter et al. 2012), and take into account the possibility that mandrills have more fluid fission-fusion dynamics than typical savannah baboons, as reported in the Guinea baboons (P. papio) (Patzelt et al. 2011). Further observations are required in relation to the duration, scale, and membership of subgrouping to examine the hypothesis.

\section{Acknowledgements}

280 Scientifique et Technologique in Gabon, for the research permission. I thank also the Kyoto City

281 Zoo and Dr. Delphine Verrier at the CIRMF for the training on the age-sex classification, 282 Professor Juichi Yamagiwa, Dr. Yoshihiro Nakashima, Dr. Katharine Abernethy and two 283 reviewers for their beneficial comments, Koumba Sylvain, Biviga Steven, Nzamba Victor, and 284 all the field assistants for their cooperation. This work was supported by the JSPS KAKENHI 285 Grant Numbers 19107007, 60166600, 12J01884, and by PROCOBHA project funded by 286 JST/JICA, Science and Technology Research Partnership for Sustainable Development 287 (SATREPS). 


\section{References}

290 Abernethy KA, White LJT, Wickings EJ (2002) Hordes of mandrills (Mandrillus sphinx): extreme group size and seasonal male presence. J Zool Lond 258:131-137

292 Altmann J (1980) Baboon mothers and infants. Harvard University Press, Cambridge

293 Altmann J, Hausfater G, Altmann SA (1985) Demography of Amboseli baboons, 1963-1983. Am J Primatol 8:113-125

295

312 Grueter CC, Chapais B, Zinner D (2012) Evolution of multilevel social systems in nonhuman

Astaras C, Mühlenberg M, Waltert M (2008) Note on drill (Mandrillus leucophaeus) ecology and conservation status in Korup National Park, southwest Cameroon. Am J Primatol 70:306310

Aurelli F, Schaffner CM, Boesch C, Bearder SK, Call J, Chapman CA, Connor R, Di Fiore A, Dunbar RIM, Henzi SP, Holekamp K, Korstjens AH, Layton R, Lee P, Lehmann J, Manson JH, Ramos-Fernandez G, Strier KB, van Schaik CP (2008) Fission-fusion dynamics: new research frameworks. Curr Anthropol 49:627-654

Bret C, Sueur C, Ngoubangoye B, Verrier D, Denoubourg J-L, Petit O (2013) Social structure of a semi-free ranging group of mandrills (Mandrillus sphinx): a social network analysis. Plos One 8:e83015. doi:10.1371/journal.pone.0083015

Crook JH, Gartlan JS (1966) Evolution of primate societies. Nature 210:1200-1203

Devreese L, Huynen MC, Stevens JMG, Todd A (2013) Group Size of a Permanent Large Group of Agile Mangabeys (Cercocebus agilis) at Bai Hokou, Central African Republic. Folia Primatol 84:67-73

Gartlan JS (1970) Preliminary notes on the ecology and behavior of the drill, Mandrillus leucophaeus Ritgen, 1824. In: Napier JR, Napier PH (eds) Old world monkeys, Academic Press, New York, pp 445-473 
primates and humans. Int J Primatol 33:1002-1037

314 Grüter CC, Zinner D (2004) Nested societies: convergent adaptations of baboons and snub-nosed monkeys? Primate Report 70:1-98

Harris EE (2000) Molecular systematics of the Old World monkey tribe Papionini: analysis of the total available genetic sequences. J. Hum Evol 38:235-256

Henzi P, Barrett L (2003) Evolutionary ecology, sexual conflict, and behavioural differentiation among baboon populations. Evol Anthropol 12:217-230

Hoshino J, Mori A, Kudo H, Kawai M (1984) Preliminary report on the grouping of mandrills (Mandrillus sphinx) in Cameroon. Primates 25:295-307

Itani J (1977) Evolution of primate social structure. J Hum Evol 6:235-243

Kappeler PM, van Schaik CP (2002) Evolution of primate social systems. Int J Primatol 23:707740

Kudo H (1987) The study of vocal communication of wild mandrills in Cameroon in relation to their social structure. Primates 28:289-308

Kummer H (1968) Social organization of hamadryas baboons: a field study. The University of Chicago Press, Chicago and London

Mitani M (1989) Cercocebus torquatus: Adaptive feeding and ranging behaviors related to seasonal fluctuations of food resources in the tropical rain forest of south-western Cameroon. Primates 30:307-323

332 Mori U (1979) Individual relationships within a unit. In: Kawai M (ed) Ecological and sociological studies of gelada baboons. Kodansha, Tokyo, pp. 93-124

334 Ohsawa H (1979) The local gelada population and environment of the Gich area. In: Kawai M (ed) Ecological and sociological studies of gelada baboons. Kodansha, Tokyo, pp. 3-46

336 Patzelt A, Zinner D, Fickenscher G, Diedhiou S, Camera B, Stahl D, Fischer J (2011) Group 
composition of Guinea baboons (Papio papio) at a water place suggests a fluid social organization. Int J Primatol 32:652-668

R Core Team (2013) R: a language and environment for statistical computing. R Foundation for Statistical Computing, Vienna, Austria. http://www.R-project.org/

Range F, Fischer J (2004) Vocal Repertoire of Sooty Mangabeys (Cercocebus torquatus atys) in the Taï National Park. Ethology 110:301-321

Rhine RJ (1975) The order of movement of yellow baboons (Papio cynocephalus). Folia Primatol 23:72-104

Rhine RJ, Forthman DL, Stillwell-Barnes R, Westlund BJ, Westlund HD (1979) Movement patterns of yellow baboons (Papio cynocephalus): the location of subadult males. Folia primatol 32:241-251

Rhine RJ, Tilson R (1987) Reactions to fear as a proximate factor in the sociospatial organization of baboon progressions. Am J Primatol 13:119-128

Rogers ME, Abernethy KA, Fontaine B, Wickings EJ, White LJT, Tutin CEG (1996) Ten days in the life of a mandrill horde in the Lopé Reserve, Gabon. Am J Primatol 40:297-313

Setchell JM, Charpentier M, Wickings EJ (2005) Sexual selection and reproductive careers in mandrills (Mandrillus sphinx). Behav Ecol Sociobiol 58:474-485

Setchell JM, Dixson AF (2002) Developmental variables and dominance rank in adolescent male mandrills (Mandrillus sphinx). Am J Primatol 56:9-25

Setchell JM, Lee PC, Wickings EJ, Dixson AF (2002) Reproductive parameters and maternal investment in mandrills (Mandrills sphinx). Int J Primtol 23:51-68

Setchell JM, Wickings EJ (2003) Sequence and timing of dental eruption in semi-free-ranging mandrills (Mandrillus sphinx). Folia Primatol 75:121-132

360 Shultz S, Opie C, Atkinson QD (2011) Stepwise evolution of stable sociality in primates. Nature 
362

363

Silk JB, Altmann J, Alberts SC (2006) Social relationships among adult female baboons (papio cynocephalus) I. variation in the strength of social bonds. Behav Ecol Sociobiol 61:183195

Snyder-Mackler N, Beehner JC, Bergman TJ (2012) Defining higher levels in the multilevel societies of geladas (Theropithecus gelada). Int J Primatol 33:1054-1068

Sueur C, Petit O (2010) Signals use by leader in Macaca tonkeana and Macaca mulatta: groupmate recruitment and behaviour monitoring. Anim Cogn 13:239-248

Swedell L (2011) African papionins: diversity of social organization and ecological flexibility. In: Cambell CJ, Fuentes A, MacKinnon KC, Panger M, Bearder SK (eds) Primates in Perspective. Oxford University Press, New York, pp 241-277

Swedell L, Schreier A (2009) Male aggression towards females in hamadryas baboons: conditioning, coercion, and control. In: Muller MN, Wrangham RW (eds) Sexual coercion in primates and humans: an evolutionary perspective on male aggression against females. Harvard University Press, Cambridge, pp. 244-268

Takenoshita Y, Ando C, Iwata Y, Yamagiwa J (2008) Fruit phenology of the great ape habitat in the Moukalaba-Doudou National Park, Gabon. Afr Study Monogr Suppl.39:23-39

White EC, Dikangadissi J-T, Dimoto E, Karesh WB, Kock MD, Abiaga NO, Starkey R, Ukizintambara T, White LJT, Abernethy KA (2010) Home-range use by a large horde of wild Mandrillus sphinx. Int J Primatol 31:627-645

Zinner D, Peláez F, Torkler F (2001) Group composition and adult sex-ratio of hamadryas baboons (Papio hamdryas hamadryas) in central Eritrea. Int J Primatol 22:415-430 
384 Table 1 Age-sex classes and references on physical and social development.

\begin{tabular}{|c|c|c|}
\hline Age-sex class ${ }^{* 1}$ & Estimated age & Definition / Physical and social development \\
\hline Infant (I) & $0-12$ months & Smallest individual which hangs onto its mother \\
\hline Juvenile (J) & $1-3$ years & Small animal which travels independently \\
\hline $\begin{array}{l}\text { Adult female } \\
\text { (AF) }\end{array}$ & $\geq 4$ years & $\begin{array}{l}\text { Fully grown female. There are two categories of AF in the progressions: FI } \\
\text { (judged as AF because it has an infant) and non-FI (judged as AF only } \\
\text { when genital was observed, else indistinguishable from PM) / } \\
\text { Average females give the first birth at } 4.6 \text { yrs in captivity (Setchell et al. } \\
\text { 2002) }\end{array}$ \\
\hline $\begin{array}{l}\text { Pubescent male } \\
\text { (PM) }\end{array}$ & 4-5 years & $\begin{array}{l}\text { Body size is similar to adult female and testes are small / } \\
\text { Testes descend at } 3.8 \text { yrs and canines appear at } 4.8 \text { yrs (Setchell and Dixson } \\
\text { 2002; Setchell and Wickings 2003) }\end{array}$ \\
\hline $\begin{array}{l}\text { Subadult male } \\
\text { (SM) }\end{array}$ & 6-9 years & $\begin{array}{l}\text { Body size larger than female and testes volume increased / } \\
\text { Testes volume and testosterone level increase, second sexual adornment } \\
\text { emerge, and most males become peripheral at 6-7 yrs (Setchell and } \\
\text { Dixson 2002) }\end{array}$ \\
\hline $\begin{array}{l}\text { Adult male } \\
\text { (AM) }\end{array}$ & $\geq 10$ years & $\begin{array}{l}\text { Fully grown male / } \\
\text { Attain full body length and mass at } 10 \text { yrs and some males associate with } \\
\text { group (Setchell and Dixson 2002) }\end{array}$ \\
\hline
\end{tabular}

I was capable of conducting the age-sex classification because I had undergone training at the Centre International de Recherches Médicales de Franceville (CIRMF), Gabon and Kyoto City Zoo, Japan.

*1: Abernethy et al. (2002) used a little different categorization from this study: infant was 0-12 months old, juvenile was 1-2 years old, adult female was $>3$ years old, and males were divided into four classes (3-4 years, 5 years, 6-9 years and $>10$ years old). 
386 Table 2 Age-sex class compositions of Mandrillus sphinx and other African papionins. Parentheses mean the percentage of individuals in the group.

\begin{tabular}{|c|c|c|c|c|c|c|c|c|c|c|c|c|}
\hline Species & Study sites & Horde/group size & I & $\mathrm{J}$ & $\mathrm{AF}$ & PM & $(\mathrm{AF}$ or $\mathrm{PM})$ & SM & $\mathrm{AM}$ & UN & SSR & References \\
\hline M. sphinx & Moukalaba/Case 1 & 169 (subgroup) & $10(5.9 \%)$ & $67(39.6 \%)$ & $10(5.9 \%)^{* 1}$ & - & $68(40.2 \%)^{* 1}$ & $11(6.5 \%)$ & $3(1.8 \%)$ & 0 & - & This study \\
\hline M. sphinx & Moukalaba/Case 2 & 350 & $33(9.4)$ & $129(36.9)$ & $124.7(35.6)$ & $35.3(10.1)$ & & $23(6.6)$ & $5(1.4)$ & 0 & 4.5 & This study \\
\hline M. sphinx & Moukalaba/Case 3 & 442 (subgroup) & $47(10.6)$ & $141(31.9)$ & $171.5(38.8)$ & $41.5(9.4)$ & & $32(7.2)$ & $6(1.4)$ & $3(0.7)$ & 4.5 & This study \\
\hline M. sphinx & Lopé $(\mathrm{n}=20)$ & $338-845$ & $\begin{array}{l}9-175 \\
(1.4-25.7)\end{array}$ & $\begin{array}{l}100-340 \\
(19.0-51.2)\end{array}$ & $\begin{array}{l}94-288 \\
(22.9-44.6)\end{array}$ & $\begin{array}{l}59-171 \\
(11.5-24.7)\end{array}$ & & $\begin{array}{l}6-32 \\
(0.8-5.9)\end{array}$ & $\begin{array}{l}1-17 \\
(0.1-3.8)\end{array}$ & & $3.0-33.1$ & Abernethy et al. 2002 \\
\hline M. sphinx & Lopé (n = 3) & $449-625$ & $\begin{array}{l}38-86 \\
(8.1-13.8)\end{array}$ & $\begin{array}{l}73-200 \\
(16.3-45.8)\end{array}$ & - & - & $\begin{array}{l}247-312 \\
(39.5-57.0)\end{array}$ & $\begin{array}{l}56-83 \\
(11.4-14.3)\end{array}$ & $\begin{array}{l}21-30 \\
(3.4-5.2)\end{array}$ & & - & Rogers et al. 1996 \\
\hline M. sphinx & Campo $(n=4)$ & $15-80$ & - & - & - & - & & - & $1-6(6.5-8.3)$ & & $6.5-8.3^{* 2}$ & Hoshino et al. 1984 \\
\hline P. hamadryas & Eritrea $(n=6)$ & 139.2 & $12.8(8.6)$ & $39.8(26.8)$ & $58.3(42.8)$ & - & & $7.8(6.2)$ & $20.3(15.7)$ & & 2.4 & Zinner et al. 2001 \\
\hline P. hamadryas & Various sites ${ }^{* 3}$ & $38-146$ & & & $28.5-58$ & & & & $9-30$ & & $1.1-2.8^{* 2}$ & Swedell 2011 \\
\hline T. gelada & Gich Plateau $(n=3)$ & 103.0 & $13.0(18.7)$ & $31.3(22.9)$ & $37.7(37.0)$ & $2.3(1.7)$ & & $3.3(4.4)$ & $15.3(15.2)$ & & 2.0 & Ohsawa 1979 \\
\hline T. gelada & Various sites ${ }^{* 3}$ & $60-271$ & & & 59 & & & & 16 & & $3.7^{* 2}$ & Swedell 2011 \\
\hline P.cynocephalus & Amboseli $(\mathrm{n}=3)$ & 34.3 & $1.7(4.9)$ & $7.7(22.3)$ & $15.7(45.6)$ & $3.3(9.7)$ & & $1.0(2.9)$ & $5.0(14.6)$ & & 2.7 & Altmann et al. 1985 \\
\hline P. cynocephalus & Various sites ${ }^{* 3}$ & $31-80$ & & & $11.5-22$ & & & & $5-12$ & & $1.3-4.4^{* 2}$ & Swedell 2011 \\
\hline P. anubis & Various sites ${ }^{* 3}$ & $15-115$ & & & $3.9-38$ & & & & $2.3-17$ & & $1.1-9.5^{* 2}$ & Swedell 2011 \\
\hline P. ursinus & Various sites ${ }^{* 3}$ & $20.5-79$ & & & $11-31$ & & & & $2-13.3$ & & $2.1-10.3^{* 2}$ & Swedell 2011 \\
\hline Cercocebus spp. & Various sites ${ }^{3-3}$ & $10.5-89$ & & & $2.2-23$ & & & & $1-9$ & & $1.75-4.0^{* 2}$ & Swedell 2011 \\
\hline C. agilis & Bai Hokou $(n=4)$ & 135.5 & $10.8(7.9)$ & $52.3(38.5)$ & $48.3(35.6)$ & - & & - & $\begin{array}{l}24.3 \text { (17.9) } \\
\text { (SM included) }\end{array}$ & & 2.0 & Devresse et al. 2013 \\
\hline
\end{tabular}

The mean values are shown except mandrills. The comparison must be conducted roughly because the age-sex classifications are slightly different among studies and species.

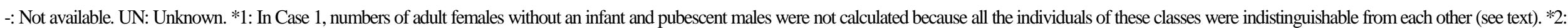
Subadult males are not included for calculations because their numbers are not available. *3: These data are based on Fig. 15.4 in Swedell (2011). Ranges of mean value are shown in the table. 


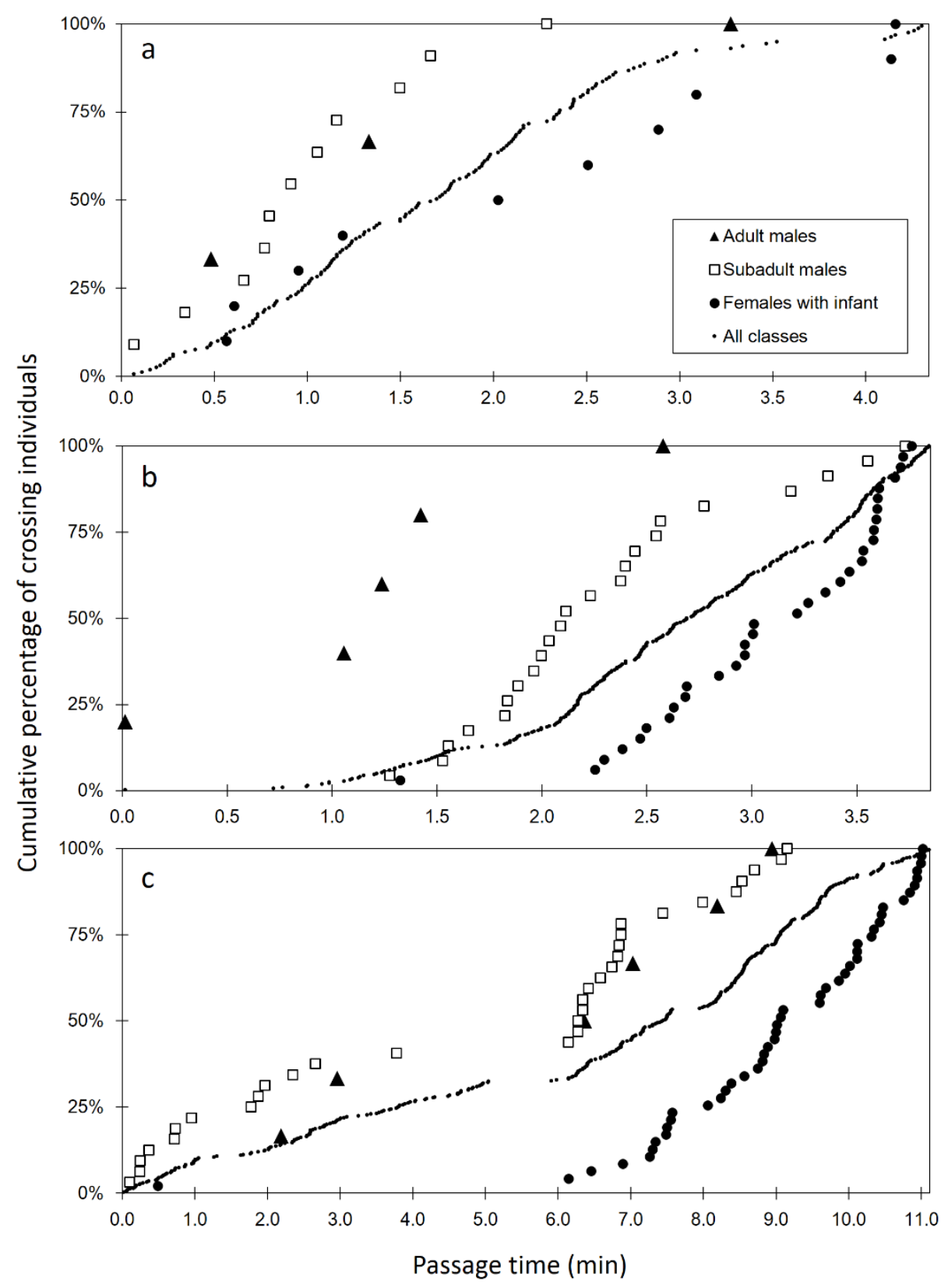

389 Fig. 1 Cumulative percentage of individuals in each age-sex class over the passage time. 1a Case 1. 1b

390 Case 2. 1c Case 3. Individuals who repassed reversely have not been included. Small dots (all classes) mean

391 all individuals that passed the open place other than the dependant infants; thus, the classes whose points

392 are located above them tend to concentrate in the front part of the progression, and ones below the small

393 dots tend to be in the rear. 
395 Online Resource 1 Video image of a progression of mandrills in Case 1. A subgroup crossed a fallen tree 396 over a river.

397

398 Online Resource 2 Video image of a progression of mandrills in Case 2. A horde crossed a logging road 3992 m wide. 